\title{
Optimization Model and Application Research for Logistics Network Facilities within Beijing-Tianjin-Hebei Region
}

\author{
Luan Luan 1, a, Xifu Wang 1, b, Yang Lv 1, c and Ze Gao 2, d \\ ${ }^{1} S$ chool of Traffic and Transportation, Beijing Jiaotong University, Beijing 100000, China \\ ${ }^{2}$ Beijing far - Communication Technology Co., Ltd, Beijing 100000, China \\ a16120859@bjtu.edu.cn, bxfwang1@bjtu.edu.cn, ${ }^{c} 13120798 @ b j t u . e d u . c n,{ }^{d}$ rebacca_yj@163.com
}

Keywords: Beijing-Tianjin-Hebei region; Logistics network; Hub-and-Spoke network optimization; Hub location.

\begin{abstract}
In the context of integration of Beijing, Tianjin and Hebei, logistics integration has become an important matter for logistics industry and regional economics. While the infrastructures are getting completed, the cost is still high and the efficiency is relatively low. Under such circumstance, optimizing the logistics structure of Beijing-Tianjin-Hebei area would increase the efficiency of functioning and resource utilizing. Being the effective structure on integration of traffic resource, lowering traffic cost, increasing operating efficiency, the axis-radiate structure should get enough attention and research, in order to optimize the whole Beijing-Tianjin-Hebei (BTH) region logistics structure.
\end{abstract}

\section{Introduction}

\subsection{Research Background}

Beijing-Tianjin-Hebei regional logistics integration as the prerequisite for regional development of the Beijing-Tianjin-Hebei region has become an important national development strategy. The geographical advantage of the natural resources within the Beijing-Tianjin-Hebei region to integrate the use of resources become a necessity, which is the core of the development of integrated logistics content. The optimal allocation of the logistics network in Beijing, Tianjin and Hebei region should fully consider the construction of the transportation infrastructure network in the region and maximize the possible integration and utilization of the three-phase logistics network in Beijing, Tianjin and Hebei to improve the efficiency and stability of the logistics network.

\subsection{Research Significance}

Logistics integration is the key content of Beijing-Tianjin-Hebei regional coordinated development, and the planning of logistics network and the construction of transportation infrastructure are the basic prerequisites of logistics industry development. Flow network node layout as a key component of the logistics network content will affect the efficiency of the entire logistics activities. With the development of Beijing-Tianjin-Hebei regional integration strategy, the structure of the logistics network and infrastructure construction are facing greater challenges, if not fundamentally improve the operational efficiency of the logistics network, it is bound to become an important restriction factor of regional logistics Integration development in Beijing-Tianjin-Hebei region. Therefore, the logistics network optimization configuration has a very important guiding significance and theoretical significance.

\section{Overview of the Hub-and-Spoke Network Optimization}

\subsection{The Structure of Logistics Network}

Logistics network is defined as: the logistics nodes and their connections at all levels as the basis and the basic logistics activities for the touch point to the Internet as a link between information technology to form a link with each other for the system network architecture. Therefore, logistics nodes and logistics lines are the basis for the implementation of logistics network. 


\subsection{Conception of the Hub-and-Spoke Network}

A transport services system that constitutes a number of hub cities and other non-hub cities and hubs of hub cities and radiation cities aims to meet the need of Beijing-Tianjin-Hebei region, and the locomotion of goods and people transport services

\subsection{The characteristics of Hub-and-Spoke Network}

Compared with the other network structures, hub-and-spoke network has its own advantages, but also can not be avoided shortcomings. However, such as a large logistics network like the BeijingTianjin-Hebei region, hub-and-spoke network can bring the positive effect more than the negative one.

\section{Hub-and-Spoke Network Optimization Model and Algorithm Research}

\subsection{Model Assumptions}

This paper make the following basic assumptions:

(1) The flow of goods between the originating nodes in the network and the unit transportation costs of different modes of transport are known;

(2) The time and inter-city transport service time limit between each pair of origin and destination in the network are known. When the goods transit, it is necessary to consider the time delay caused by the transit of the goods at the hub. The delay time reflects through the delay coefficient;

(3) One node in a network can only have one hub at most.

(4) The transit between the start and the end through a maximum of two hub transport, and the starting point to the hub and hub to the end of the transport can only use road transport.

\subsection{Symbol Description}

This section describes the notation of sets, variables, decision variables, and parameters associated with the model.

(1) The relevant sets are defined as follows:

$\mathrm{N}$-a collection of nodes in the network for each city;

S-a collection of transport modes;

(2) The relevant variables are defined as follows:

$\mathrm{f}_{\mathrm{ij}}$ - represents the flow of goods from node $\mathrm{i}$ to node $\mathrm{j}$;

$\mathrm{d}_{\mathrm{ij}}$ - represents the distance from node $\mathrm{i}$ to node $\mathrm{j}$;

(3) Decision variables are defined as follows:

$$
\begin{gathered}
X_{i j}^{1}=\left\{\begin{array}{l}
1, \text { direct transport is allowed between nodes } i \text { and } j \\
0, \\
\text { else }
\end{array}\right. \\
X_{i j k m}^{s}= \begin{cases}1, \text { The transport between }(i, j) & \text { uses transport } s \text { through the hub of }(k, m) \\
0, & \text { else }\end{cases} \\
y_{k}=\left\{\begin{array}{ll}
1, \text { City } k \text { is chosen as the hub } \\
0,
\end{array} ; H_{k s}= \begin{cases}1, \text { Hub } k \text { can provide transport mode } t \\
0, & \text { else }\end{cases} \right.
\end{gathered}
$$

(4) The relevant parameters are defined as follows:

$\mathrm{C}^{\mathrm{s}:}$ the unit price of goods; $\mathrm{S} \in\{1,2\}, \mathrm{s}=1$ represents road transport, $\mathrm{s}=2$ represents railway transport; $\mathrm{F}_{\mathrm{k}}$ - represents the fixed cost of establishing and operating the hub at node $\mathrm{K} ; \mathrm{T}_{\mathrm{ij}}^{\mathrm{s}}$ - represents transit time from city $\mathrm{i}$ to city $\mathrm{j}$ using the mode of transport $\mathrm{s}$; $\mathrm{TW}_{\mathrm{ij}}$-represents the service time requirement for goods transport from origin to destination; $\mathrm{MC}_{\mathrm{ks}}$-represents the transit service cost of the mode of transport at the hub; P-the number of alternative hubs; $\alpha$-represents discount coefficient of the economic scales; $\beta$ - represents the time delay coefficient at the hub, $\beta>1$.

\subsection{Hub-and-Spoke Network Optimization Model}

The final objective function is:

$$
\begin{aligned}
\text { MinZ } & =\sum_{i, j \in N} f_{i j} c^{1} d_{i j} X_{i j}+\sum_{i, j, k, m \in N} f_{i j} X_{i j k m}^{1} \alpha c d_{k m}+\sum_{i, j, k, m \in N, \mathrm{~s} \in S \backslash\{1\}} f_{i j} X_{i j k m}^{s} c^{s} d_{k m}+ \\
& \sum_{i, j, k, m \in N, \mathrm{~s} \in S} f_{i j} X_{i j k m}^{s}\left(c^{1} d_{i k}+c^{1} d_{m j}\right)+\sum_{k \in N, \mathrm{~s} \in S} M C_{k t} H_{k t}+\sum_{k \in N} F_{k} y_{k}
\end{aligned}
$$


Subject to:

$$
\begin{aligned}
& \sum_{k \in N} y_{k}=P \\
& X_{i j k m}^{s} \leq y_{k}, \forall i, j, k, m \in N, \mathrm{~s} \in S \\
& X_{i j k m}^{s} \leq y_{m}, \forall i, j, k, m \in N, \mathrm{~s} \in S \\
& \sum_{i, j, k, m \in N} X_{i j k m}+X_{i j}=1, \forall i, j \in N \\
& X_{i j k m}^{s} \leq H_{k s}, \forall i, j, k, m \in N, \mathrm{~s} \in S \\
& X_{i j k m}^{s} \leq H_{m s}, \forall i, j, k, m \in N, \mathrm{~s} \in S \\
& \sum_{k \neq m, \mathrm{~s} \in S}\left(X_{i j k m}^{s}\left(T_{i k}^{1}+\beta T_{k m}^{s}+T_{m j}^{1}\right)+X_{i j} T_{i j}^{1}\right) \leq T W_{i j}, \forall i, j \\
& \sum_{k \in N} X_{i j k k}^{1}\left(T_{i k}^{1}+T_{k j}^{1}\right)+X_{i j} T_{i j}^{1} \leq T W_{i j}, \forall i, j \\
& X_{i j k m}^{s} \in\{0,1\}, \forall i, j, k, m \in N, \mathrm{~s} \in S \\
& X_{i j} \in\{0,1\}, \forall i, j \in N \\
& y_{k} \in\{0,1\}, \forall k \in N \\
& H_{k s} \in\{0,1\}, \forall k \in N, \mathrm{~s} \in S
\end{aligned}
$$

In the above model, the formula (3-1) is the objective function, and the formulas (3-2) to (3-13) are the constraints.

\section{Analysis on Optimization Result of Beijing - Tianjin - Hebei Logistics Network Based on Hub-and-Spoke}

\subsection{Data Sources}

The data of Beijing-Tianjin-Hebei regional hub-and-spoke network is based on the administrative divisions of Beijing, Tianjin and Hebei. Finally, a set of nodes consisting of 29 nodes is selected as the selected set of hub location.

\subsection{Analysis of Logistics Network Optimization}

In this study, several factors, such as the number of hubs, transit time limit and scale factor, are used to design the full-factor experiment to find the lowest total network cost. The combinations of the different factor levels are shown in Table 1.

Table 1. The set of effective factor

\begin{tabular}{|c|c|}
\hline Experimental design parameters & Experimental design level \\
\hline Number of hubs $p$ & $\{4,5,6,7\}$ \\
\hline Transit time limit TW & $\{2,3,4\}$ \\
\hline Discount factor $\alpha$ & $\{0.45,0.6,0.9\}$ \\
\hline
\end{tabular}

After several optimization calculations, when the parameter value of $p=6, \alpha=0.45$ and $\mathrm{TW}_{\mathrm{ij}}=4 \mathrm{~T}_{\mathrm{ij}}^{1}$, the total cost of this model make the lowest, and the optimal function value of $1.73 \mathrm{e}+16$ Yuan. Selected as the hub city node is number $5,8,9,15,24,27$, all the six hub nodes are highway hub. The construction of hub-and-spoke logistics network is shown in Figure 1. 


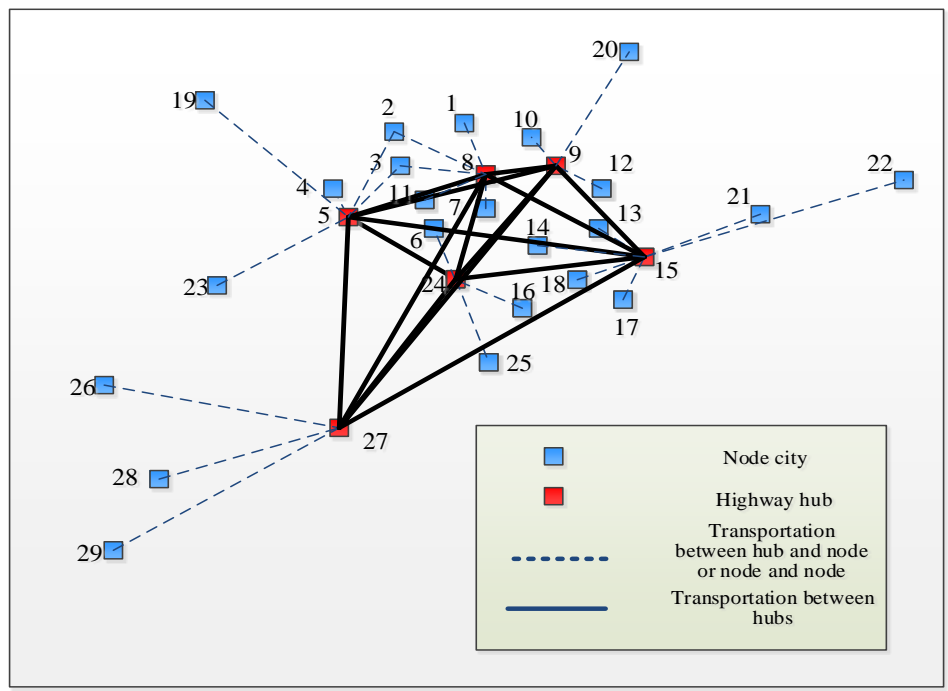

Figure 1. The partial optimal routing distribution mode among cities

As is shown in Fig. 1, hub nodes 5, 8, 9, 15, 24, and 27 are all highway nodes, mainly because the distances between the nodes in this region are relatively close and the advantages of railway transportation can not be realized.

\section{Conclusion}

In this paper, the following main research work is carried out:

(1) Construction of Beijing-Tianjin-Hebei Regional Logistics Network Optimization Model Based on Hub-and-spoke Network.

Based on the analysis of hub-and-spoke network and the integration of Beijing-Tianjin-Hebei regional logistics, the hub-and-spoke logistics hub location and path allocation optimization model is constructed. And the model is solved by the constructed model.

(2) Solution of Beijing-Tianjin-Hebei Logistics Network Optimization Model

Using Matlab programming, the optimization model of Beijing-Tianjin-Hebei logistics network is solved, and the construction scheme of Beijing-Tianjin-Hebei regional logistics network based on hub-and-spoke network is obtained.

\section{References}

[1] Campbell J F. Hub Location and the p-Hub Median Problem [J]. Location Science, 1997, 5 (3) : 203-203.

[2] Alumur S A, Kara B Y, Karasan O E. Multimodal hub location and hub network design [J]. Omega, 2012, 40(6):927-939.

[3] Bodin L, Levy L. The arc oriented location routing problem [J]. 1989, 27:74-94.

[4] Nagy G, Salhi S. A nested location-routing heuristic using route length estimation [J]. Studies in Locational Analysis, 1996, 10(10):109-127.

[5] Ishfaq R, Sox C R. Hub location-allocation in intermodal logistic networks [J]. European Journal of Operational Research, 2011, 210(2):213-230. 